\title{
New technologies of enhanced plastic for use in rail vehicles to reduce noise emissions
}

The article presents an overview of modern plastics for use in rail vehicles. The analysis of plastics and composites in the constructional aspect was analyzed. The trends in the development of polymer materials, technologies and constructions used in the manufacture of vehicles, on the one hand, are determined by the technical and economic requirements of industry and, on the other, by the continued emphasis on reducing fuel consumption and $\mathrm{CO}_{2}$ emissions. Further development will be subject to pre-impregnation techniques, particularly in the form of different types of reinforcement. Full use of the advantages of reinforced polymer materials in vehicle production will only be achieved when further optimization of the resin properties and development of automation will result in the widespread use of composite components in series production. Observing the trends and pace of development, it is possible to predict that there are still restrictions on the use of polymeric materials in the transport sector, such as relatively high prices, technological constraints and the hindering automation of large-scale production. Modern construction and material solutions, in particular those using reinforced plastics, are primarily designed to reduce vehicle weight and have better noise and vibration damping properties. Rail vehicles are becoming more environmentally friendly at the time and travel comfort is higher.

Key words: rail vehicles, new materials, plastics and composites, $\mathrm{CO}_{2}$ emissions

\section{Introduction}

Plastics consists of individual elements - molecules. After these small elements are linked into chains, large or very large molecules are formed and make up macromolecules. Thermoplastics and plastomers are the main types of plastics that consist of linear or branched macromolecular chains that are not connected to one another (fig. 1b). Due to their many beneficial properties, thermoplastics have a significant contribution in the process of designing vehicles. Thermoplastics can be melted and dissolved many times. This has a very high significance, particularly with regard to environmental protection. If individual types are not mixed with one another, thermoplastics are ideally suited for recycling, since new parts can theoretically made from used ones [4]. Another benefit they offer is that they can be heat-sealed, so it is possible to remove cracks and scratches. Elastomers are the next group, where both stronger and weaker bonds between macromolecules are possible, resulting in diverse cross-linking. In the case where a small number of neighboring molecular chains are joined by bonds, plastics - i.e. elastomers - are formed (fig. 1c). Elastomers neither melt nor dissolve, however they have good stretch properties, with qualities similar to rubber. Elastomers are frequently present in rail vehicles as seals, but thermoplastic elastomers (fig. 1d) are most commonly used to make spoilers, as their structure is made up of co-polymers consisting of hard and soft blocks or a mixture of thermoplastics with (non-cross-linked or partially cross-linked) rubber. Duroplastics are the third group, in which a greater number of cross-links makes the material harder but also more brittle. A large number of molecular chains form one large cross-linked network. Such a strongly cross-linked plastic is called a duroplastic, or hardening plastic. Duroplastics can neither be melted nor dissolved. The capacity for stretching, present in elastomers, also disappears. However duroplastics are resistant to heat. For this reason, they are used to make engine chamber body parts, for example. Innovative design and materials solutions, particularly those applying reinforced plastics, mainly lead to reduction of vehicle weight and attenuation of noise and vibrations. Thus, the vehicle is more environmentfriendly and comfortable. a)

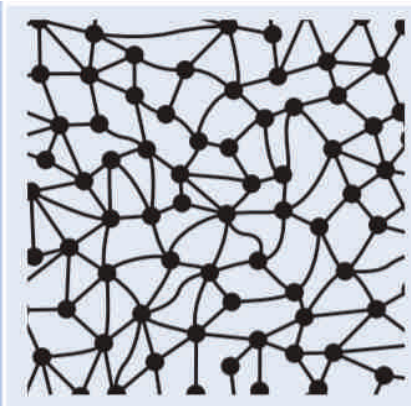

b)

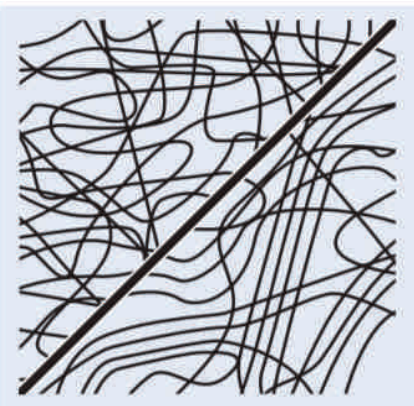

c)

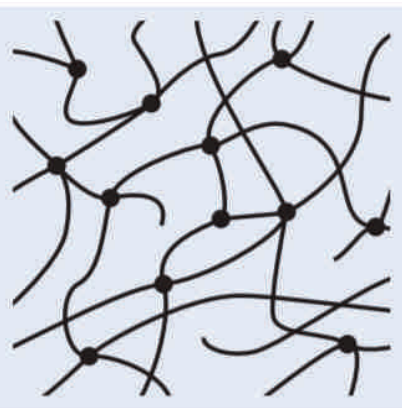

d)

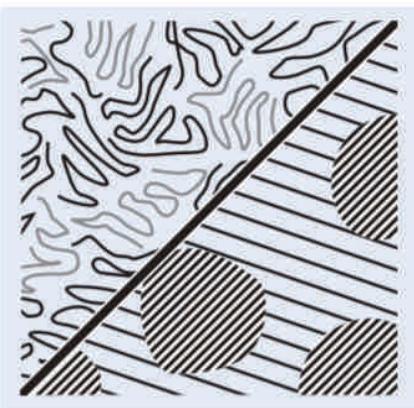

Fig. 1. Structure: a) duroplastic, b) termoplastic, c) elastomer, d) thermoplastic elastomer 
The next group consists of laminates (composites), made up of at least 2 materials. They exhibit different properties than their individual components. A reinforcing substance is a material that significantly improves the properties of laminates or makes it possible to obtain certain composites. The remaining material, ensuring cohesion between the components, is the matrix. Laminates can be divided into the following categories:

- layered laminate composites,

- fibrous composites,

- particle composites,

- infiltrated composites.

Multi-layered composites (Fig. 2) are also being used increasingly frequently, and these are composites where the matrix is made up of a polymer or plastic. Fibrous composites (FVK) are particularly important in this case. The reinforcing material consists of natural or synthetic fibers (organic and/or non-organic). These fibers can be short, long and unterminated, or they may be present in the form of products like unwoven fabric, mats, woven fabric or knitted fabric. By combining the fibers with the matrix (in an oriented or unoriented manner), mechanical and thermal properties are improved, such as tensile strength, breaking strength, thermal resistance and modulus of elasticity.

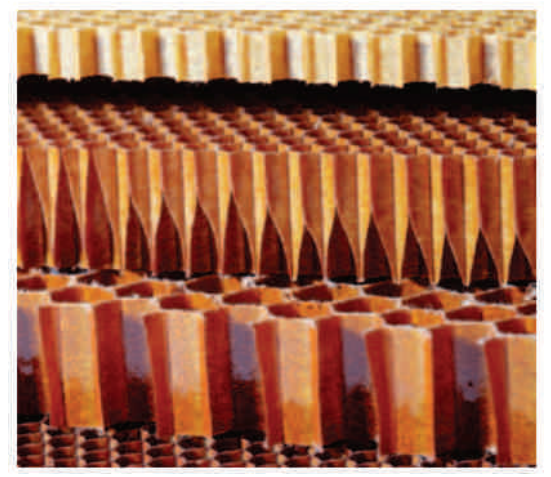

Fig. 2. Composites reinforced with amide fibers with a macromolecular structure

The application of plastics in vehicle design is an expression of energy savings in comparison to steel and aluminum. This is not only due to lower operating costs but also lower costs of producing, processing and machining the material itself. Eliminating plastics in vehicle design would increase energy demand by $26 \%$. Plastics will be a necessity in mass-scale industry in the foreseeable future, and one should also account for the fact that reducing a vehicle's weight by $100 \mathrm{~kg}$ reduces fuel consumption by up to $0.6 \mathrm{dm}^{3} / 100 \mathrm{~km}$, thus reducing $\mathrm{CO}_{2}$ emissions by 13 $\mathrm{g} / \mathrm{km}[1,2]$.

Currently, plastics have a $23 \%$ share in vehicles, and by 2030, this percentage is expected to grow to approx. $70 \%$. According to the current trend, plastics are applied on the exterior of a vehicle (approx. 50\%), e.g. sheathing, bodywork. In a vehicle's interior, plastics (approx. 30\%) mainly serve to improve comfort and reduce noise. Parts and assemblies in the drive chamber are applications of plastics (approx. 20\%) in which there are heavy working conditions. Thermoplastics and hardening plastics find broad applications in vehicle design due to their properties. Reinforced plastics from both groups are dominant in these applications. The chemicals industry is engaged in intensive cooperation with vehicle manufacturers, offering materials fit to purpose more and more frequently. This does not just involve the proper mechanical properties but also other qualities, e.g. enabling the application of plastic parts in elevated temperatures, suitability for industrial lacquering. Although it is generally recognized that metals are characterized by higher strength than plastics, this is often not the case when reinforced plastics enter into the comparison. Specific strength, or the ratio of strength to density $\sigma \gamma$ is particularly interesting, because for many plastics (particularly reinforced plastics), this strength exceeds values determined for metals, as illustrated in Fig. 3.

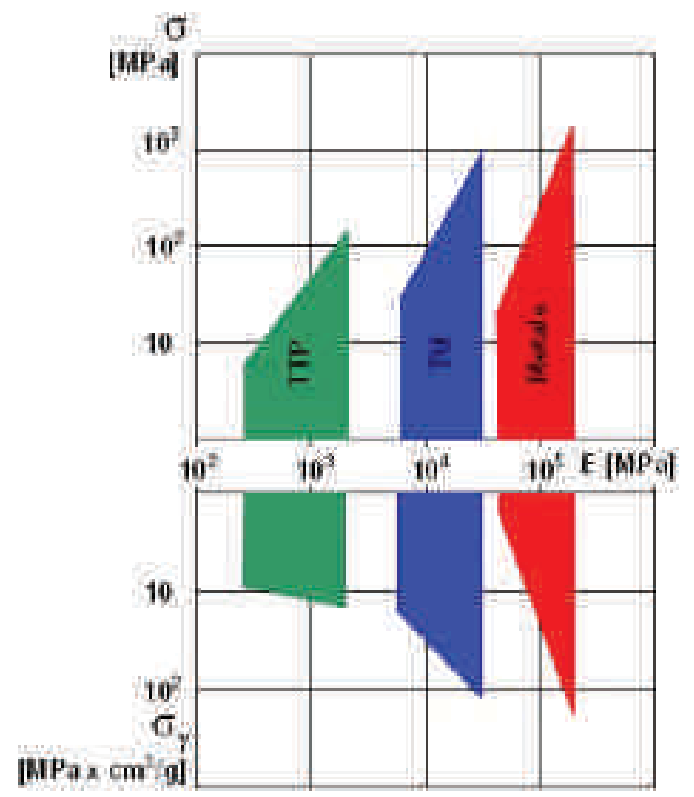

Fig. 3. Selected mechanical properties of plastics in comparison with metals (TTP - thermoplastics, TU - hardening plastics)

Linear thermal expansion $\alpha$ is an important property of plastics that is accounted for in vehicle design. Plastics exhibit linear thermal expansion 10 times that of metals. However, this does not apply to polymer composites, which have thermal expansion that is twice as high (glass reinforcement) or sometimes even lower (carbon reinforcement) compared to steel. In the case where plastics are applied as parts located near a heat source, their resistance to elevated temperatures is particularly important. As working temperature increases, the material's strength and rigidity decrease significantly. The chemicals industry currently offers polymers that can be used at temperatures up to $300^{\circ} \mathrm{C}$. The acoustic features of polymer materials provide greater comfort and also have a pro-environmental impact. Sound waves propagate much more slowly in plastics than in metals, so they are perfect noise-damping materials. Sound wave absorption is greater the less elastic the plastic is. Plastic vehicle parts themselves also emit less noise.

\section{Modern materials and technologies}

The properties of plastics used in transport are generally the effect of modifications, including the addition of rein- 
forcing agents. The resultant polymer material (granulate, resin) is an inhomogeneous material composed of at least two phases: the matrix and the reinforcing agents embedded in it (i.e. carriers, reinforcement). The latter particularly include fibers in various forms (cut, long, continuous) made from various materials. The carriers introduced into the matrix affect most properties: strength grows, as does maximum working temperature, the thermal expansion coefficient decreases, etc. Among the various carriers, organic and non-organic materials of natural origin are being used more and more frequently. Although jute, sisal, hemp and other fibers do not increase the material's strength and Young's modulus significantly, they may meet essential requirements posed towards certain vehicle subassemblies while being well-perceived for environmental reasons. Examples of applications of natural fibers for reinforcement of polypropylene (PP) vehicle parts are:

- shelves, door guard, soffit ceiling finishing - curaua, kenaf, sisal or jute fibers,

- noiseproofing and insulating elements for doors, floor, etc. - cotton, linen, hemp and sisal fibers.

In recent years, nanomaterials have been introduced as an additive to polymers in order to reinforce them or endow parts with specific properties. Particles based on montmorillonite are most commonly used to reinforce polyamides and polypropylene. Nanoparticle-containing polyamides are used to manufacture covers, parts of the fuel system while polypropylene is used to make dashboards with increased resistance to scratches and dirt. Synthetic materials are used decidedly more often as carriers than natural materials. Certain organic materials can be distinguished in this group, such as oriented polyethylene fibers, aramid fibers, as well as non-organic materials - glass, mineral fibers, e.g. wollastonite (calcium metasilicate with aciform structure) and others.

The following reinforcements can be differentiated according to form:

- particles and dispersions, e.g. powders, micro-spheres, flakes, etc.,

- fibers, rowing, wires, whiskers, nanotubes, etc.,

- mats, unwoven fabric, tapes, etc.,

- plaited fabric, etc.

Most of the aforementioned carriers are used to reinforce plastics applied in parts manufacturing. Parts reinforced with short glass fibers are dominant among those manufactured from thermoplastics, although carbon fiber reinforcement is being applied with increasing frequency despite high materials and technological costs. This is due to the material's high static and fatigue strength as well as its pleasing aesthetic even without additional coatings, even on parts installed outdoors. The reduced weight of parts with carbon reinforcement in comparison to steel parts (60\% lighter) and aluminum parts (25\% lighter) is also not without significance. Hybrid parts, structural assemblies, load-bearing structures and complete vehicle bodies are all potential applications of the aforementioned materials. Polyamides are the thermoplastics most commonly used as load-bearing parts of vehicles, particularly PA66, reinforced by up to 60 glass fibers. PA6 and PA66 with glass fibers (GF30, GF35) are used to make collectors, and with the addition of $15 \%$ mineral fillers and glass fibers (GF25) also covers. PA66 (GF35) is also applied in the drive system, pneumatic springs, etc. In the motorization industry, polyamides are also applied in the form of mixtures with other thermoplastics. The polyamide + polyphenyl ether mixture $(\mathrm{PA}+\mathrm{PPE})$ is a material characterized by significantly greater thermal resistance and thermal shape and dimensional stability. Polyamides for bodywork applications are the effect of cooperation between the chemicals and motorization industries. Cathode Dip Painting (CDP) followed by the drying operation at up to $200^{\circ} \mathrm{C}$ does not result in loss of the part's shape and dimensional stability $[5,7,8]$. Similarly to other thermoplastics, reinforced polyamides are generally processed by means of conventional methods. In typical cases, granulate containing a specific quantity of fibers cut to a certain length (within the 0.3-10 $\mathrm{mm}$ range) is used. Fibers may also be introduced into the plastic via processing, and mixing occurs in the plasticizing system of the injection molder. It is also possible to mix the plastic with fibers in a separate process by means of compounding machines, where fibers are introduced in the form of roving or cut, or by continuously saturating fiber bands with melted polyamide (pultrusion method) and cutting them into granulate (the fibers are oriented). Introducing long fibers to a polymer matrix improves the material's directional reinforcement even further. The production technology for thermoplastics was recently mastered, although it was already known for parts made from hardened resins. Polyamides (PA66, PA6), PP, polybutyl terephthalate (PBT) and polyacetal (POM) are the polymers reinforced most often. Parts of the bodywork and load-bearing structures for fastening headlights, etc. are made using the method of pressing plasticized thermoplastic reinforced with long glass fiber (LFT - Long Fiber Thermoplastics).

Another technology for manufacturing structural elements from plastics reinforced with long fibers, delivered in the form of roving, is realized by means of a process line consisting of a compounding machine (machine used to prepare the plastic and additives for processing), doubleworm injection molder and high-speed press (Fig. 4).

Another technology is also used to process polyamides, $\mathrm{PP}$, polyethylene terephthalate (PET), which are reinforced with fibers about $25 \mathrm{~mm}$ in length. In such cases, IMC (Injection Molding Compounder) technology, combining the continuous compounding process and the cyclic injection process, is applied. Polyurethanes (PUR) are another type of plastic commonly used in vehicle design. Depending on the components, modifiers and molding technology, the properties of manufactured parts differ significantly. On one hand, the material in foamed form is capable for significant energy absorption and attenuation of vibrations, which is why it is used in bumpers and parts with insulatingnoiseproofing properties, and on the other hand, in bulk form, it is resistant to elevated temperatures. 


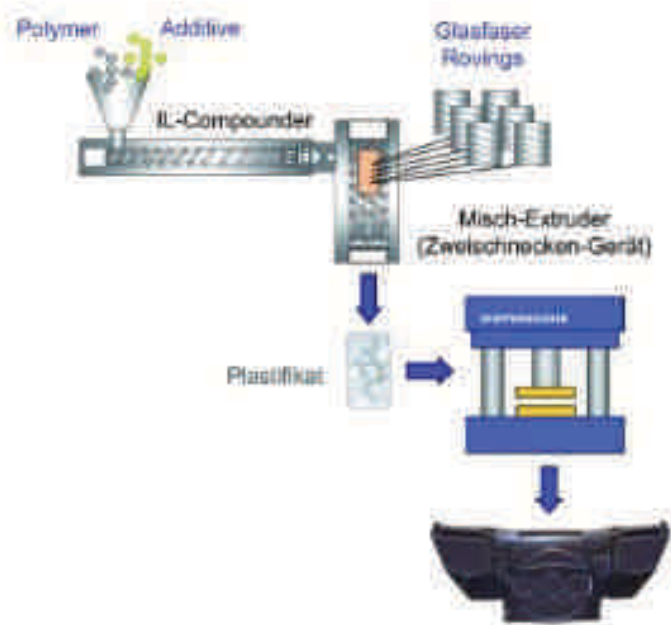

Fig. 4. Technology of molding parts made from plastic reinforced with long fibers

The plastic is characterized by high impact resistance at low temperatures, low thermal expansion (after reinforcement), low moisture absorption, and it meets requirements posed towards bodywork elements, even in a warm and humid climate. The technology of injecting reactive ingredients (polyol and isocyanate) with the addition of cut fiber - R-RIM (Reinforced Reaction Injection Molding) has been used in parts manufacturing for many years. Pressing techniques are also applied to manufacture bodywork elements from thermoplastics reinforced with continuous fiber $[5,6]$. Reinforcing fibers form structures formed by textile techniques (woven fabrics, knitted fabrics) in this case. In this manner, the so-called "organic sheets" are created, whose final shape is endowed by forming in the pressing tool. Another technique for manufacturing sheathing elements is to polymerize the plastic (e.g. casting polyamide) in a mold filled with continuous fibers. For several years now, hybrid designs combining a metal part and plastic have been applied in vehicle design. The metal part is most often shaped by plastic working and mounted in the socket of the mold, into which thermoplastic is injected. This technology reduces the weight of manufactured parts while simultaneously increasing their strength and rigidity. Production costs are generally lower, and designers gain greater freedom in shaping the body. The technology described above has successfully been applied to manufacture the front belt, rear cover and other structural elements. Long or continuous fibers are applied to reinforce the structure in certain cases. Significant improvement of a part's strength is achieved in the case where "hybrid plus" technology is applied, in which ribbing made from fiber-reinforced PP is injected onto steel drawpieces.

Hardened plastic parts are most often molded from plastics obtained using BMC technology (Bulk Molding Compounds), containing reinforcements like glass fiber and others. The injection and pressing process is used to manufacture even large-sized window frames for the motorization industry. Numerous examples of applications of polymer composite parts can be seen in vehicles that are currently being manufactured. These are mainly parts of the exterior sheathing and shaped parts made from composites with glass and carbon reinforcement. Polyester resins (UP) and epoxide resins (EP), others less often, are most commonly used as the matrix. Because continuous fibers exhibit very high tensile strength, reinforcement of the structure should also ensure fiber orientation so that they are stretched during work. Polyester or epoxide body elements reinforced with layers of mat or fabric are pressed under low pressure. The process is usually performed using the RTM (Resin Transfer Molding) method, in which dosed resin saturates layers of reinforcement properly arranged in layers, and at the same time, the excess is drained off by the vacuum generated. In serial production, the industry relies on pre-impregnates obtained using SMC (Sheet Molding Compounds) technology. Depending on design requirements, semi-products with a random or oriented arrangement of cut fibers, or with unidirectionally oriented continuous fibers, can be applied. Successive versions of preimpregnates are characterized by increasingly high strength and Young's modulus. After the required outline is cut out and placed in the mold, preimpregnates are hardened in the low-pressure pressing process under the proper temperature and pressure conditions.

Hardened plastics are also used in combination with other plastics. Roofs consisting of an exterior epoxide layer, an insulating/noiseproofing layer made of foamed PUR and epoxide-glass laminate, are an example of such a solution. The entirety is made in three steps using the RTM method.

\section{Conclusions}

The directions of development of polymer materials, technology and designs with applications in vehicle manufacturing are defined by technical and economic requirements posed by the industry on one hand, and on the other, by the constant pressure from environmentalists to limit fuel consumption and $\mathrm{CO}_{2}$. This generates innovation in the scope of the applications of modern materials, methods of processing them, as well as new design solutions, and results in reduction of the vehicle's weight as well as a series of benefits in comparison to metal, which include:

- low density,

- good attenuation of sound and vibrations,

- electric insulation or regulated conductivity,

- good resistance to the action of chemicals, 
- high degree of freedom in shaping,

- permeable to electromagnetic waves,

- very good corrosion resistance,

- thermal insulation,

- possibility of modifying specific parts for specific cases of application.

Even today, the boldest forecasts show that at the current rate of technical development, a vehicle's weight will be reduced by $30 \%$ on average in the near future thanks to these materials. In the scope of materials, trends of broader applications are being outlined for modern plastics reinforced with materials such as:

- nanocomposites,

- composites reinforced with carbon fibers,

- biopolymer composites (green polymers),

- reinforced with nanotubes, carbon fibers and natural fibers,

- thermoplastic multi-material composites or multimaterial systems, e.g. laminate rein-forced with nanotubes,

- high-quality recyclates,

- modern films and coating materials.

Techniques of preparing pre-impregnates will continue

to be developed, particularly with respect to the forms of various types of reinforcement. Plaited, knitted and sown parts have found industrial applications. However, complete utilization of the advantages afforded by reinforced polymers in vehicle manufacturing will only take place when the possibility of broad application of composite parts in serial production arises as a result of further optimization of the properties of resins and the development of automation. Observing trends and the rate of development, it can be predicted that the limitations to the applications of polymers in the motorization industry that still exist, such as relatively high prices, technological conditions and difficult automation of large-series manufacturing will soon be surmounted. Modern design and materials solutions, particularly those that utilize reinforced plastics, mainly serve to reduce vehicle weight, in addition to having better noise and vibration attenuation properties. Thanks to such solutions, rail vehicles become more environment-friendly, and the comfort of travel is greater. The application of plastics at the designing stage of vehicles of this type is an expression of energy savings in comparison to steel and aluminum. This is not only due to lower operating costs but also lower costs of producing, processing and machining the material itself. Abandoning plastics used in passenger vehicle design would cause a $26 \%$ increase in energy demand [2].

\section{Bibliography}

[1] ENGELMANN, H.-J., GŁUSZEWSKI, W. Kompozyty polimer-metal w ochronie radiologicznej. Journal: Tworzywa Sztuczne w Przemyśle. 2016, 4.

[2] FELDMANN, J. Kunststoffe - Werkstoffe der Energieeffizienz. Kunststoffe im Automobilbau. VDI-Verlag 2015.

[3] GESELlA, G., SZELEZIŃSKI, A., MURAWSKI, L., MUC, A. Wykorzystanie tworzyw sztucznych w sektorze motoryzacyjnym. Wpływ temperatury pracy wytłaczarek na jakość wyrobu. Autobusy. Technika, Eksploatacja, Systemy Transportowe. 2015, 6.

\author{
Włodzimierz Stawecki, Ph.D. - Rail Vehicles Insti- \\ tute TABOR in Poznan. \\ e-mail: Sekretariat@tabor.com.pl
}

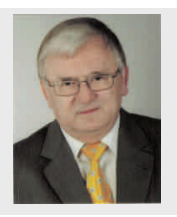

Prof. Jerzy Merkisz, DSc., DEng. - Faculty of Mechanical Engineering at University of Technology.

e-mail: Jerzy.Merkisz@put.poznan.pl
[4] HINZ, T., LEWKOWICZ, R. Wpływ kształtu elementów konstrukcyjnych nadwozi samochodowych wykonanych $\mathrm{z}$ tworzywa sztucznego na ich wytrzymałość. Mechanik. 2015, 5-6(05).

[5] KEUERLEBER, M. Kunststoff-Trends im Powertrain, Kunststoffe im Automobilbau. VDI-Verlag. 2014.

[5] KOETH, C.-P. Leichtbau - die Zweite, Automobilindustrie. $2016,3$.

[6]. KRÓLIKOWSKI, W. Tworzywa wzmocnione i włókna wzmacniające. Wydawnictwo Naukowo-Techniczne. 2010.

[7] POCHWAŁA, T., ŚLIWA, A., WALA, T. Wpływ procesu impregnacji na mikrostrukturę tworzywa ogniotrwałego. Szkło i Ceramika. 2016, 4.

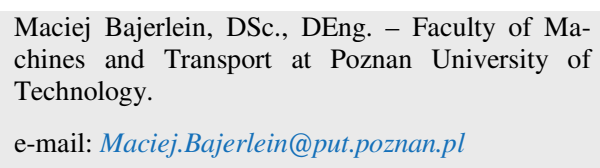

Maciej Bajerlein, DSc., DEng. - Faculty of Machines and Transport at Poznan University of Technology.

e-mail:Maciej.Bajerlein@put.poznan.pl
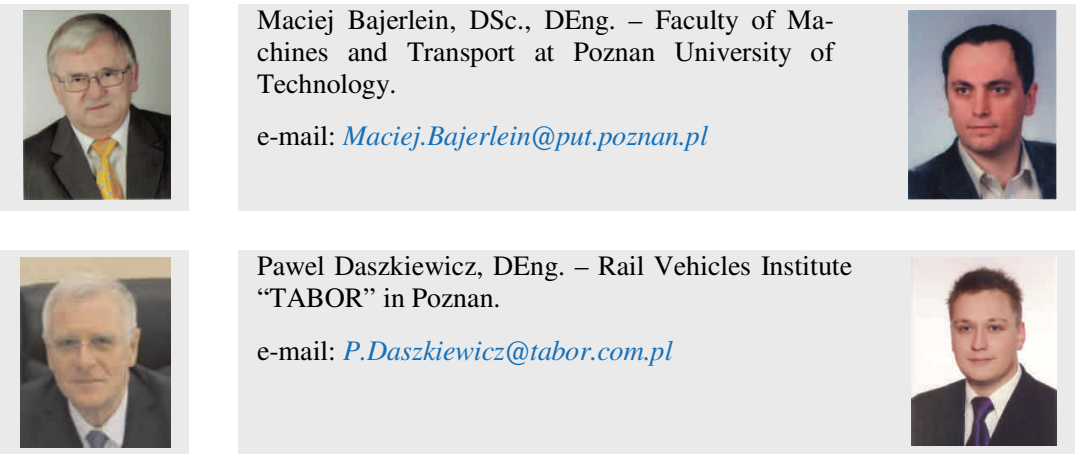

Pawel Daszkiewicz, DEng. - Rail Vehicles Institute

"TABOR" in Poznan.

e-mail: P.Daszkiewicz@tabor.com.pl 